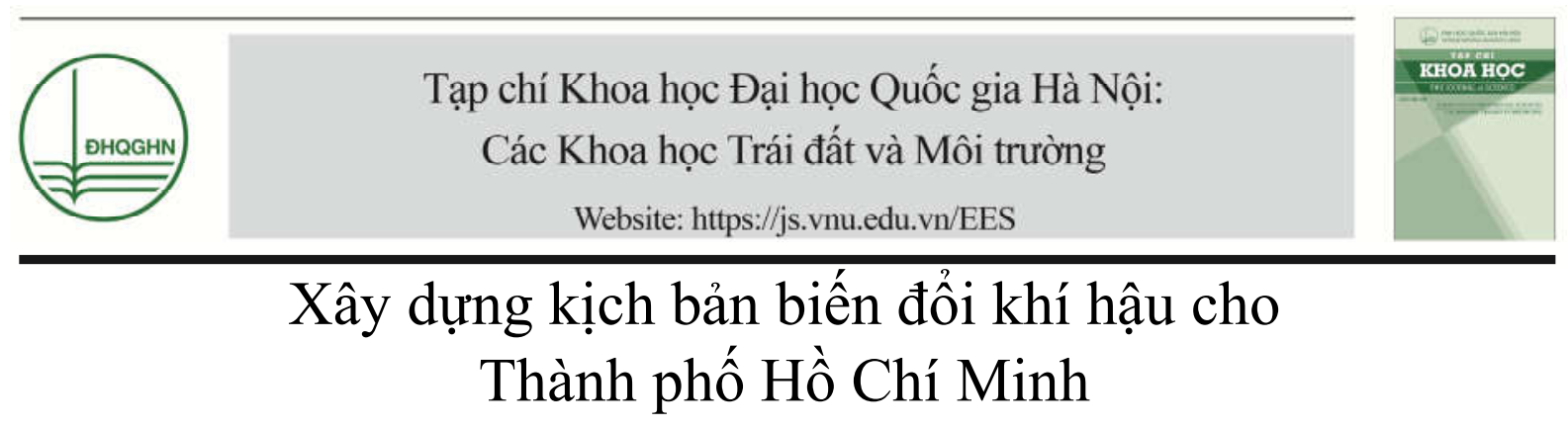

\author{
Mai Văn Khiêm* \\ Viện Khoa học Khí tương Thủy văn và Biến đổi khi hậu, \\ 23/62 Nguyễn Chí Thanh, Đống Đa, Hà Nội \\ Nhận ngày 30 tháng 11 năm 2018 \\ Chỉnh sửa ngày 10 tháng 12 năm 2018; Chấp nhận đăng ngày 25 tháng 12 năm 2018
}

\begin{abstract}
Tóm tắt: Bài báo này trình bày kết quả nghiên cứu xây dựng kịch bản biến đổi khí hậu cho khu vực Thành phố Hồ Chí Minh dựa trên nền kịch bản BĐKH của Việt Nam được công bố năm 2016 bởi Bộ Tài Nguyên và Môi Trường. Bốn mô hình khí hậu khu vực độ phân giải cao bao gồm CCAM, clWRF, PRECIS, RegCM được áp dụng để tính toán chi tiết hóa kết quả của mô hình khí hậu toàn cầu. Kết quả cho thấy, nhiệt độ trung bình năm ở Thành phố Hồ Chí Minh trong tương lai đều có xu thế tăng lên so với thời kỳ cơ sở 1986 - 2005, mức tăng phụ thuộc vào các kịch bản RCP. Đến cuối thế kỷ, nhiệt độ trung bình năm ở Thành phố Hồ Chí Minh có mức tăng khoảng $1,7 \div 1,9^{\circ} \mathrm{C}$ theo kịch bản $\mathrm{RCP} 4.5$ và $3,2 \div 3,6^{\circ} \mathrm{C}$ theo kịch bản $\mathrm{RCP} 8.5$. Trong khi đó, lượng mưa năm ở Thành phố Hồ Chí Minh có xu thế tăng ở hầu hết các thời kỳ theo cả hai kịch bản RCP. Đến cuối thế kỷ, lượng mưa năm ở Thành phố Hồ Chí Minh tăng phổ biến từ 15 đến $25 \%$ theo kịch bản RCP4.5 và $20-25 \%$ theo kịch bản RCP8.5. Lượng mưa năm ở khu vực ven biển tăng nhiều hơn so với khu vực sâu trong đất liền.
\end{abstract}

Từ khóa: Kịch bản biến đổi khí hậu, Thành phố Hồ Chí Minh.

\section{Mở đầu}

Theo Ban liên Chính phủ về biến đổi khí hậu (IPCC), kịch bản biến đổi khí hậu (BĐKH) là giả định có cơ sở khoa học và tính tin cậy về sự tiến triển trong tương lai của các mối quan hệ giữa phát triển kinh tế - xã hội, phát thải khí nhà kính $(\mathrm{KNK}), \mathrm{BĐKH}$ và mực nước biển dâng. Kịch bản $\mathrm{BĐKH} \mathrm{là} \mathrm{cơ} \mathrm{sở} \mathrm{khoa} \mathrm{học} \mathrm{quan}$

\footnotetext{
* Tác giả liên hệ. ĐT.: 84-902222041.

Email: maikhiem77@gmail.com

https://doi.org/10.25073/2588-1094/vnuees.4332
}

trọng, là đầu vào cho các mô hình đánh giá tác động, từ đó xây dựng các kế hoạch ứng phó với BĐKH. Điều khoản 4.1 và 4.8 của Công ước khung của Liên Hợp quốc về $\mathrm{BĐKH}$ (UNFCCC) quy định tất cả các thành viên buộc phải đánh giá được tổn hại do $\mathrm{BĐKH}$ và chuẩn bị các thông báo quốc gia. Trước hết là đánh giá tổn hại thông qua các ước lượng về tác động của $\mathrm{BĐKH} \mathrm{được} \mathrm{xây} \mathrm{dựng} \mathrm{dựa} \mathrm{trên} \mathrm{các} \mathrm{kịch}$ bản về khí hậu tương lai. Cho cho tới nay, IPCC đã thực hiện 5 lần xây dựng và cập nhật kịch bản BĐKH thông qua các lần báo cáo đánh giá biến đổi khí hậu: Lần thứ nhất vào năm 1990 
[1], lần thứ hai vào năm 1995 [2], lần thứ ba vào năm 2001 [3], lần thứ tư vào năm 2007 [4] và lần gần đây nhất là báo cáo lần thứ năm (AR5) trong năm 2013 [5]. Các kịch bản BĐKH của IPCC xây dựng dựa trên các mô hình động lực toàn cầu (GCM) có độ phân giải tương đối thô (khoảng $100-600 \mathrm{~km}$ ) nên khó có thể sử dụng trực tiếp sản phẩm của các mô hình này cho khu vực nhỏ mà cần thực hiện các bước chi tiết hóa và đánh giá trước khi sử dụng.

Ở Việt Nam, đã có nhiều kết quả nghiên cứu và công bố về kịch bản biến đồi khí hậu. Năm 1994, Việt Nam đã đưa ra kịch bản biến đổi khí hậu trong khuôn khổ báo cáo về biến đổi khí hậu ở châu Á của Ngân hàng phát triển châu Á. Năm 2003, kịch bản biến đổi khí hậu được xây dựng và công bố trong cho Thông báo đầu tiên của Việt Nam cho Công ước khung của Liên Hợp Quốc về biến đổi khí hậu năm [6],... Năm 2009, Bộ Tài nguyên và Môi trường đã công bố "Kịch bản biển đổi khí hậu, nước biển dâng cho Việt Nam" trên cơ sở tổng hợp các thông tin trong và ngoài nước về biến đồi khí hậu [7]. Mức độ chi tiết của các kịch bản năm 2009 giới hạn cho 7 vùng khí hậu và dải ven biển Việt Nam để kịp thời phục vụ các Bộ, ngành và các địa phương thực hiện Chương trình mục tiêu quốc gia ứng phó với biến đổi khí hậu. Đến năm 2012, Bộ Tài nguyên và Môi trường đã thực hiện cập nhật "Kịch bản biến đổi khí hậu, nước biển dâng cho Việt Nam"dựa vào các phân tích, tính toán bằng các mô hình khí hậu, công cụ thống kê [8]. Gần đây nhất, Bộ Tài nguyên và Môi trường đã cập nhật "Kịch bản biến đổi khí hậu, nước biển dâng cho Việt Nam" trên cơ sở báo cáo đánh giá lần thứ năm của IPCC [9]. Các kịch bản biến đổi khí hậu nói trên đã cung cấp thông tin về xu thế, mức độ biến đổi của nhiệt độ, lượng mưa trong quá khứ và dự tính khả năng biến đổi trong tương lai. Bên cạnh đó, một số cực trị khí hậu và hiện tượng khí hậu cực đoan cũng được đánh giá.

Dựa trên các kịch bản biến đổi khí hậu quốc gia, các địa phương cũng thực hiện chi tiết hoá kịch bản biển đổi khí hậu cấp tỉnh/thành phố dựa trên phân tích, bổ sung số liệu đo, đặc điểm địa lý,... nhằm mục đích xây dựng kế hoạch ứng phó với biến đổi khí hậu cho các ngành, lĩnh vực của địa phương.

Bài báo này trình bày các kết quả chi tiết hóa kịch bản BĐKH cho TPHCM dựa trên kịch bản $\mathrm{BĐKH}$ và nước biến dâng năm 2016 của Việt Nam. Tính chưa chắc chắn của kịch bản nhiệt độ, lượng mưa cũng được phân tích, đánh giá. Kết quả nghiên cứu là cơ sở quan trọng để cập nhật kế hoạch hành động ứng phó với biến đổi khí hậu cho Thành phố Hồ Chí Minh.

\section{Phương pháp và số liệu}

\section{Phuoong pháp}

Phương pháp chi tiết hóa động lực được sử dụng để xây dựng kịch bản BĐKH độ phân giải cao cho TPHCM. Bốn mô hình khí hậu khu vực được áp dụng bao gồm: CCAM, RegCM, PRECIS và clWRF. Mỗi mô hình có các phương án tính toán khác nhau dựa trên kết quả tính toán từ các mô hình toàn cầu của IPCC, 2013 (hình 1). Độ phân giải ngang của các mô hình CCAM, RegCM, PRECIS và $\mathrm{clWRF}$ lần lượt là $10 \mathrm{~km} \times 10 \mathrm{~km}, 20 \mathrm{~km}$ x $20 \mathrm{~km}, 25 \mathrm{~km}$ x $25 \mathrm{~km}, 30 \mathrm{~km} \times 30 \mathrm{~km}$. Chi tiết về các mô hình được mô tả trong báo cáo về cập nhật kịch bản biến đổi khí hậu và nước biển dâng năm 2016 [9].

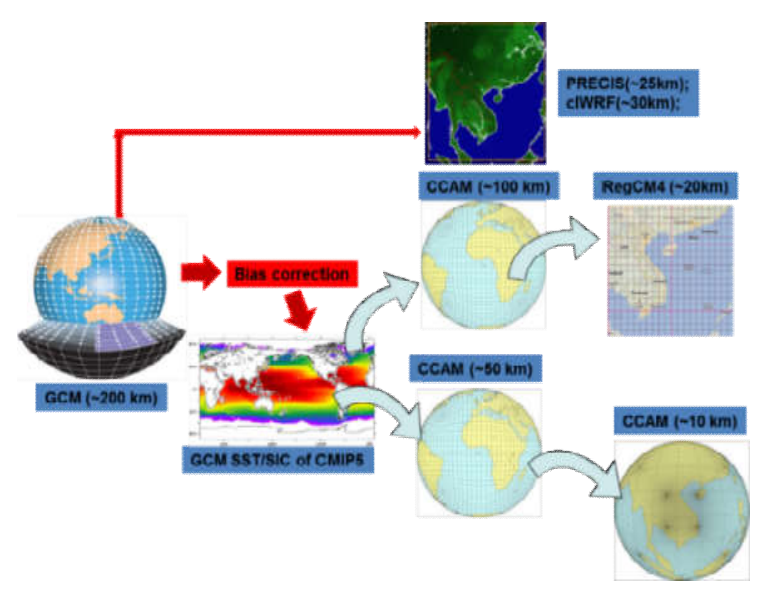

Hình 1. Sơ đồ chi tiết hóa động lực độ phân giải cao. 
Sự thay đổi của nhiệt độ và mưa được so sánh với thời kỳ cơ sở 1986 - 2005, đây cũng là giai đoạn được IPCC dùng trong báo cáo lần thứ năm $(A R 5,2013)$ [5].

Đối với nhiệt độ:

$$
\Delta T_{\text {future }}=T_{\text {future }}^{*}-\overline{T_{1986-2005}^{*}}
$$

Đối với lượng mưa:

$$
\Delta R_{\text {future }}=\frac{\left(R^{*} \text { future }-\overline{R_{1986-2005}^{*}}\right)}{\overline{R_{1986-2005}^{*}}} * 100
$$

Trong đó: $\Delta \mathrm{T}_{\text {future }}$ là biến đổi của nhiệt độ trong tương lai so với thời kỳ cơ sở $\left({ }^{\circ} \mathrm{C}\right), \mathrm{T}^{*}$ future là nhiệt độ tương lai $\left({ }^{\circ} \mathrm{C}\right), \mathrm{T}^{*}{ }_{1986-2005}$ là nhiệt độ trung bình của thời kỳ cơ sở $\left({ }^{\circ} \mathrm{C}\right) ; \Delta \mathrm{R}_{\text {future }}$ là biến đổi của lượng mưa trong tương lai so với thời kỳ cơ sở $(\%), \mathrm{R}_{\text {future là lượng mưa tương }}^{*}$ lai $(\mathrm{mm}), \mathrm{R}^{*}{ }_{1986-2005}$ là lượng mưa trung bình của thời kỳ cơ sở (mm).

Mô hình khí hậu động lực có ưu điểm là mô phỏng tốt các quá trình vật lý và hóa học trong khí quyển, tuy nhiên khó phản ánh được các yếu tố địa phương và mô hình đều tồn tại sai số hệ thống nhất định. Để khắc phục điều này, phương pháp hiệu chỉnh thống kê đã được áp dụng cho các biến nhiệt độ trung bình ngày và lượng mưa ngày tại mỗi trạm được thực hiện như sau:

\section{Hiệu chinh lương mua}

Phương pháp hiệu chỉnh phân vị (Quantile Mapping) được sử dụng để điều chỉnh kết quả tính toán lượng mưa ngày từ mô hình dựa trên số liệu quan trắc trong quá khứ tại trạm khí tượng thủy văn. Đối với mỗi phân vị của chuỗi kết quả từ mô hình, một hàm chuyển riêng biệt được xây dựng để loại bỏ sai số từ mô hình sao cho lượng mưa tính toán từ mô hình phù hợp với số liệu quan trắc tại phân vị này [10].

\section{Hiệu chỉnh nhiệt độ}

Phương pháp hiệu chỉnh dựa trên các ngưỡng phân vị được áp dụng đối với nhiệt độ [11] có thể mô tả tóm tắt như sau:

- Xây dựng hàm phân bố lũy tích đối với chuỗi nhiệt độ quan trắc cũng như nhiệt độ tính toán từ mô hình cho thời kỳ cơ sở cũng như các giai đoạn trong tương lai.

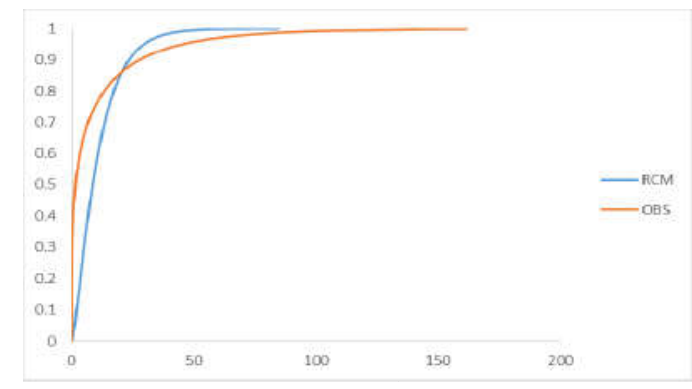

Hình 2. Minh họa phân bố luỹ tích mưa (màu đỏ: quan trắc, màu xanh: mô hình).

- Tại mỗi phân vị, hiệu chỉnh nhiệt độ tính toán từ mô hình dựa trên nhiệt độ quan trắc ứng với phân vị này. Hàm chuyển được xác định như sau:

$$
P_{i}=O_{i}+g \bar{\Delta}+f \Delta^{\prime}{ }_{i}
$$

Trong đó: $\mathrm{i}=$ phân vị thứ $\mathrm{i}$ trong chuỗi số liệu nhiệt độ quan trắc và tính toán từ mô hình, $\mathrm{O}=$ nhiệt độ quan trắc, $\mathrm{P}=$ nhiệt độ từ mô hình sau khi hiệu chỉnh, $\bar{\Delta}=\bar{S}_{f}-\bar{S}_{c}$ với $\bar{S}_{f}$ và $\bar{S}_{c}$ tương ứng là nhiệt độ trung bình chưa hiệu chỉnh giai đoạn tương lai và thời kỳ cơ sở, $\Delta^{\prime}{ }_{i}=S_{f i}-S_{c i}-\bar{\Delta}$, với $S_{f i}$ và $S_{c i}$ lần lượt là nhiệt độ chưa hiệu chỉnh của mô hình giai đoạn tương lai và thời kỳ cơ sở tại cùng một phân vị thứ i.

$$
f=\frac{\sigma_{o}}{\sigma_{S_{c}}}
$$

Trong đó: $\sigma_{S_{c}}$ và $\sigma_{o}$ là độ lệch tiêu chuẩn của chuỗi số liệu quan trắc và mô hình thời kỳ cơ sở tương ứng.

Kết quả kịch bản biến đổi khí hậu được tính toán tại các điểm trạm khí tượng trên địa bàn Thành phố Hồ Chí Minh và một số tỉnh phụ cận để lập các bản đồ phân bố không gian.

\section{Số liệu}

Số liệu được sử dụng bao gồm: (i) Số liệu tính toán từ 4 mô hình khí hậu khu vực CCAM, RegCM, PRECIS và clWRF thời kỳ 19862100; (ii) Số liệu quan trắc về nhiệt độ, lượng mưa ngày của trạm khí tượng Tân Sơn Hòa, Mạc Đĩnh Chi, Nhà Bè thời kỳ 1980-2010 được sử dụng để hiệu chỉnh kết quả của các mô hình. 


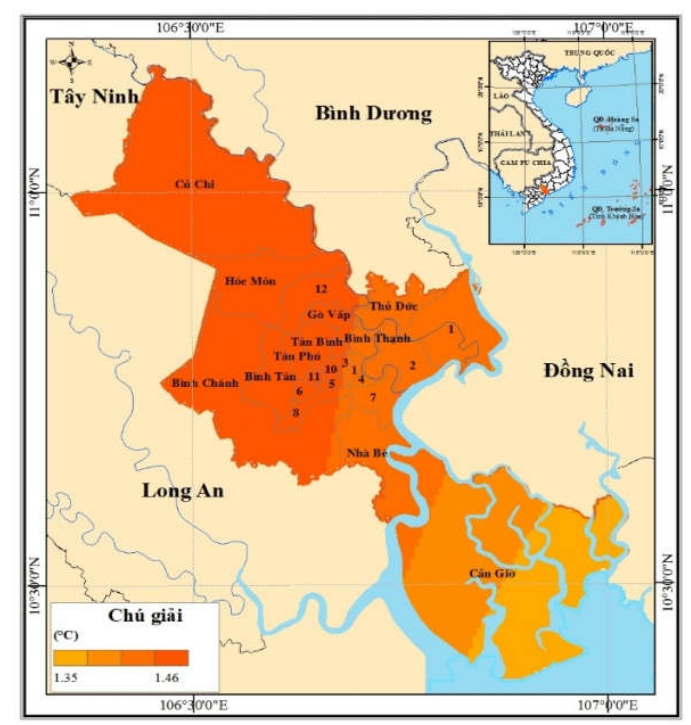

RCP4.5 - Giữa thế kỷ.

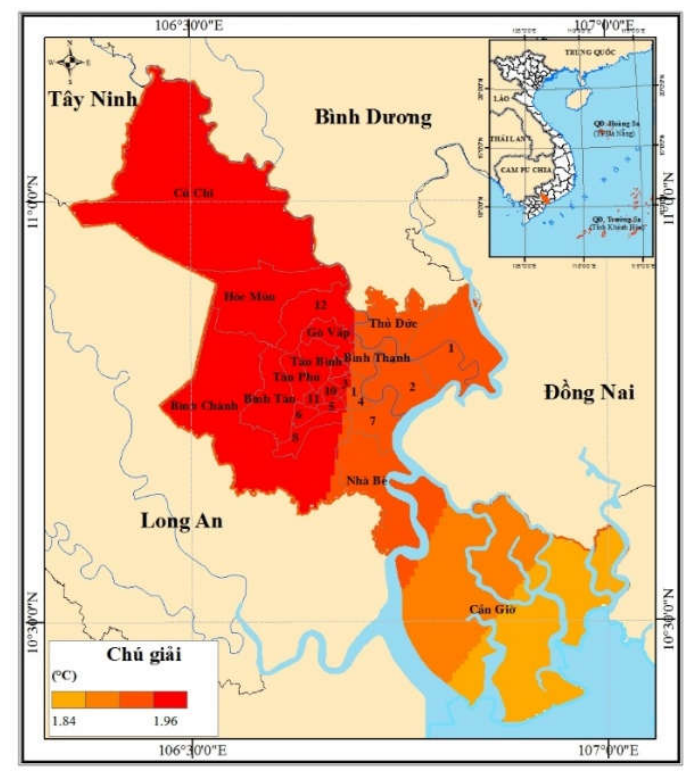

RCP8.5 - Giữa thế kỷ.

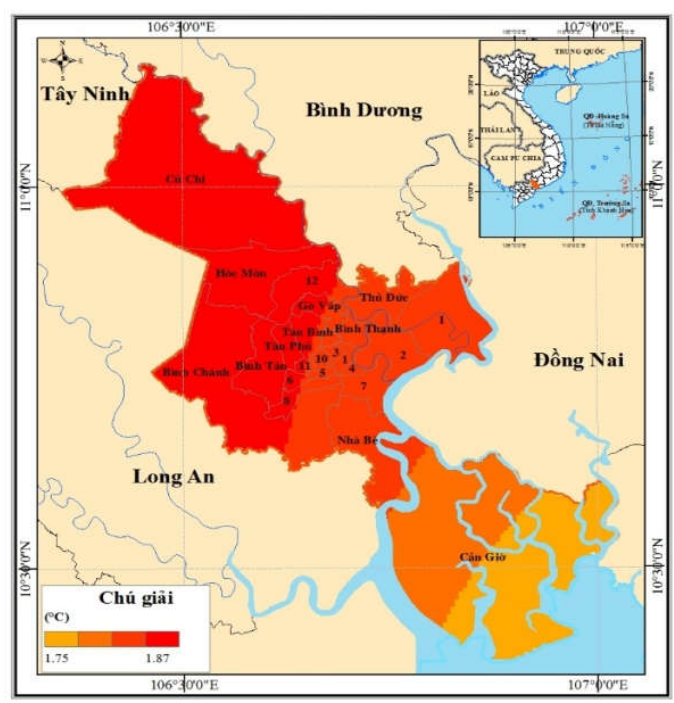

RCP4.5 - Cuối thế kỷ.

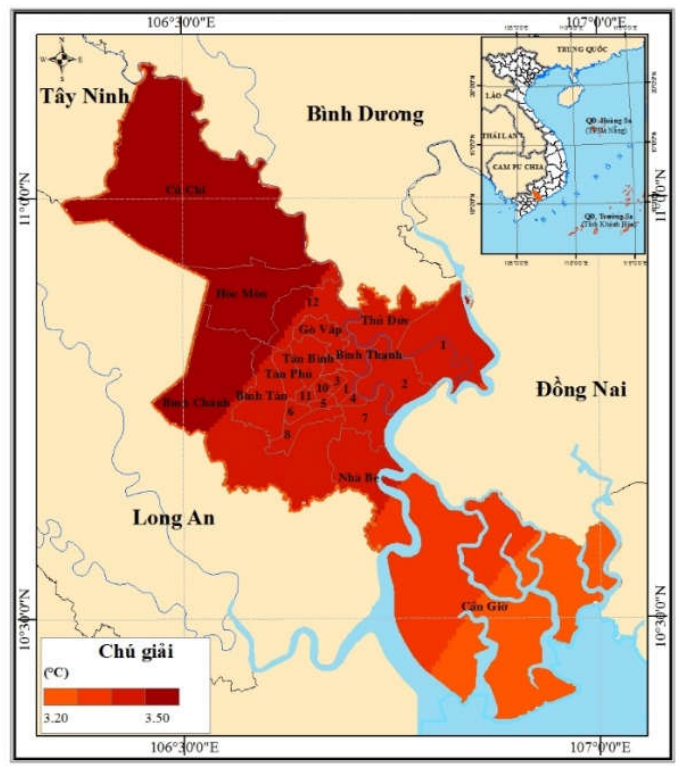

RCP8.5 - Cuối thế kỷ.

Hình 3. Biến đổi nhiệt độ trung bình năm $\left({ }^{\circ} \mathrm{C}\right)$ ở TPHCM theo kịch bản RCP 4.5 và RCP8.5.

\section{Kết quả và thảo luận}

\section{Kịch bản biến đổi khí hậu cho Thành phố Hồ Chí Minh}

Nhiệt độ trung bình: Theo kịch bản RCP4.5, vào đầu thể kỷ 21 , nhiệt độ trung bình năm ở TPHCM tăng $0,6 \div 0,7^{\circ} \mathrm{C}$ so với thời kỳ cơ sở; giữa thế kỷ có mức tăng khoảng $1,3 \div$ $1,5^{\circ} \mathrm{C}$; đến cuối thế kỷ tăng $1,7 \div 1,9^{\circ} \mathrm{C}$. Theo kịch bản RCP8.5, vào đầu thế kỷ tăng $0,8 \div$ $0,9^{\circ} \mathrm{C}$; giữa thế kỷ tăng phổ biến $1,8 \div 2,0^{\circ} \mathrm{C}$; vàđến cuối thế kỷ mức tăng lên đến $3,2 \div$ $3,6^{\circ} \mathrm{C}$. Khu vực tây bắc thành phố có mức tăng cao hơn so với khu vực đông nam (hình 3). 


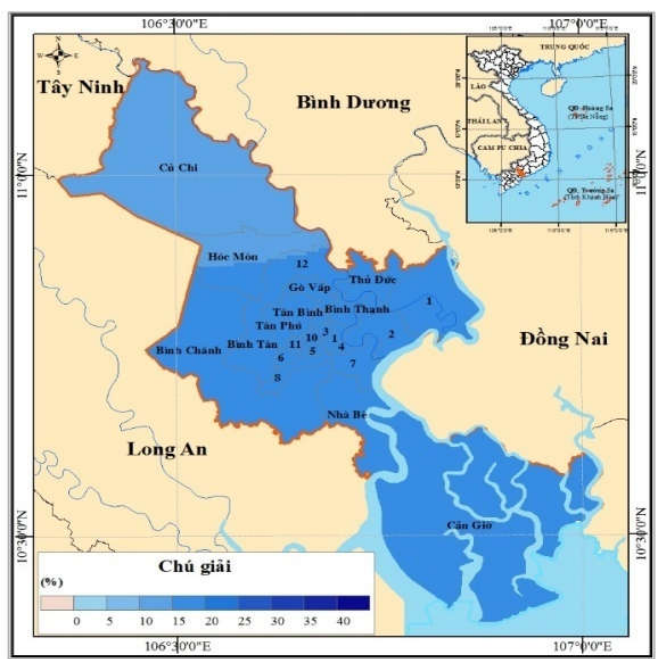

RCP4.5 - Giữa thế kỷ.

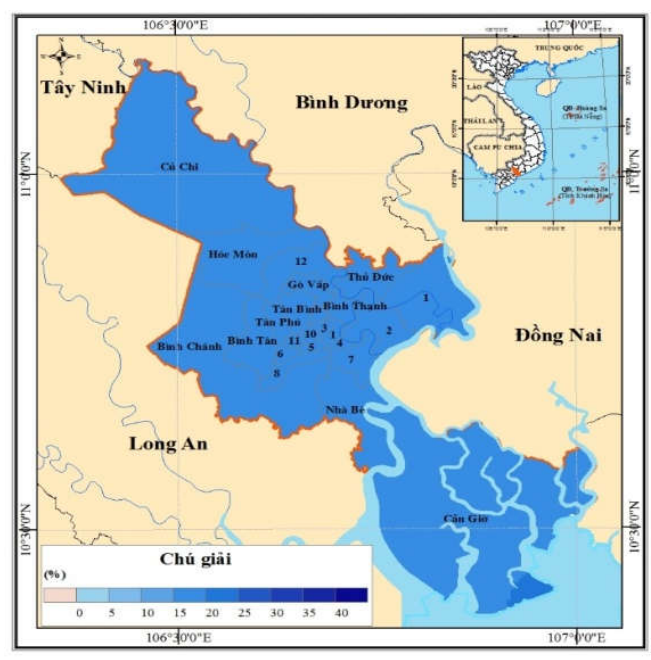

RCP8.5 - Giữa thế kỷ.

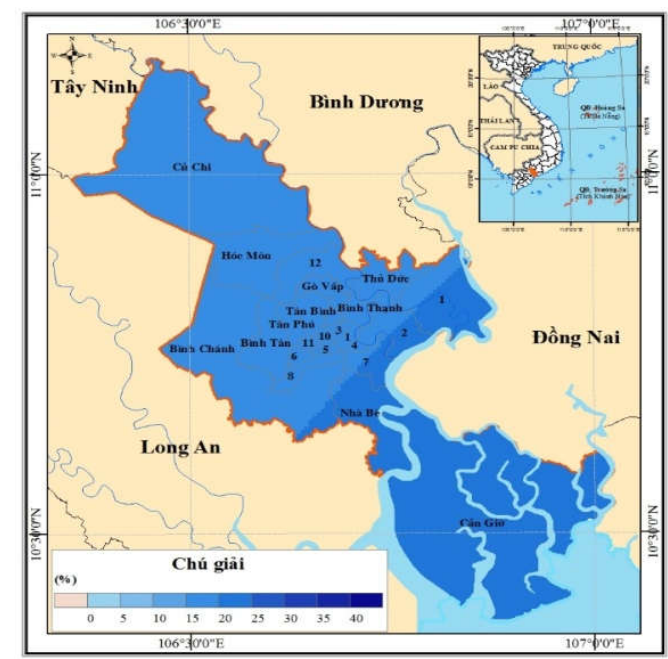

RCP4.5 - Cuối thế kỷ.

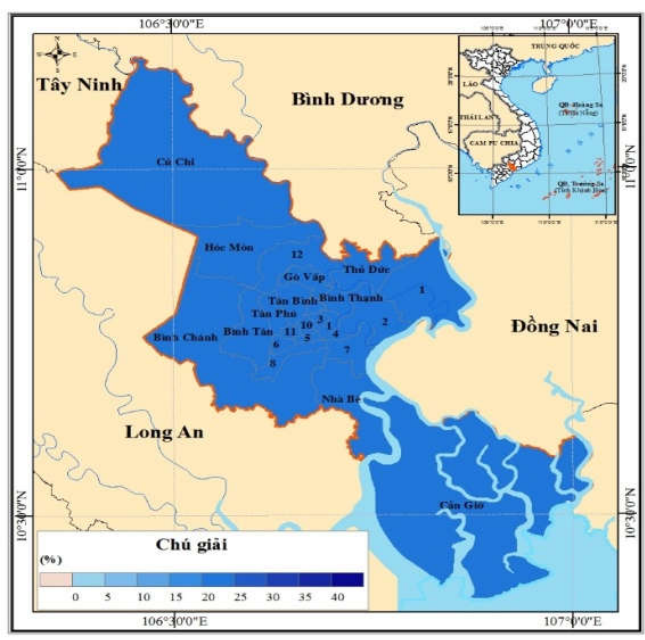

RCP8.5 - Cuối thế kỷ.

Hình 4. Biến đổi lượng mưa năm ở Thành phố Hồ Chí Minh theo kịch bản RCP4.5 và RCP8.5.

Luợng mua: Theo kịch bản RCP4.5, lượng mưa năm vào đầu thế kỷ tăng khoảng $5 \div 20 \%$ so với thời kỳ cơ sở; giữa thế kỷ tăng $10 \div 20 \%$; và đến cuối thế kỷ tăng phổ biến $15 \div 25 \%$. Ở khu vực phía đông nam, lượng mưa tăng nhiều hơn so với khu vực phía tây bắc. Theo kịch bản RCP8.5, mức tăng có sự khác biệt so với kịch bản RCP4.5, vào đầu thế kỷ, tăng $0 \div 10 \%$; giữa thế kỷ tăng $15 \div 20 \%$; đến cuối thế kỷ tăng $20 \div 25 \%$, tăng nhiều nhất ở phía đông nam của TPHCM (hình 4).
2. Mức độ chưa chắc chắn trong các kịch bản biến đổi khi hậu

Mức độ chưa chắc chắn của các kịch bản BĐKH được xác định theo kết quả tính toán của tất cả các phương án tính.

Đối với nhiệt độ, mức độ chưa chắc chắn được đánh giá theo phân vị 10 (cận dưới) và phân vị 90 (cận trên). Theo kịch bản RCP4.5, khoảng biến đổi của nhiệt độ bình năm của TPHCM vào đầu thế kỷ, giữa thế kỷ, và cuối 
thế kỷ tương ứng là $0,4 \div 1,2^{\circ} \mathrm{C} ; 1,0^{\circ} \mathrm{C} \div 2,1^{\circ} \mathrm{C}$; và $1,2^{\circ} \mathrm{C} \div 2,7^{\circ} \mathrm{C}$. Theo kịch bản $\mathrm{RCP} 8.5$, khoảng biến đổi tương ứng là $0,5 \div 1,3^{\circ} \mathrm{C} ; 1,4 \div$ $2,8^{\circ} \mathrm{C}$; và $2,8 \div 4,7^{\circ} \mathrm{C}$ (hình 5 , bảng 1 ).

Đối với lượng mưa năm, mức độ chưa chắc chắn được đánh giá theo phân vị 20 (cận dưới) và phân vị 80 (cận trên). Theo kịch bản RCP4.5, khoảng biến đổi của lượng mưa năm của TPHCM vào đầu thế kỷ, giửa thế kỷ và cuối thế kỷ tương ứng là $11,4 \div 21,3 \% ; 10,5 \% \div 28,6 \%$; và $6,7 \% \div$ $37,5 \%$. Theo kịch bản RCP 8.5 , khoảng biến đổi tương ứng là $10 \div 19,3 \% ; 14,6 \% \div 27 \%$ và $13,2 \div 33,9 \%$ (hình 6 , bảng 1 ).

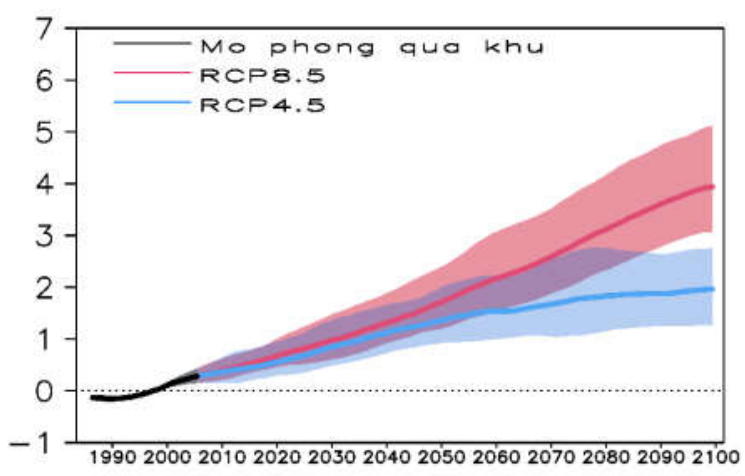

Hình 5. Mức độ chưa chắc chắn của các kịch bản về nhiệt độ $\left({ }^{\circ} \mathrm{C}\right)$ trung bình năm.

(vùng màu xanh, màu đỏ là khoảng dao động của thay đổi nhiệt độ từ phân vị 10 đến 90 tương ứng với kịch bản RCP4.5 và RCP8.5).

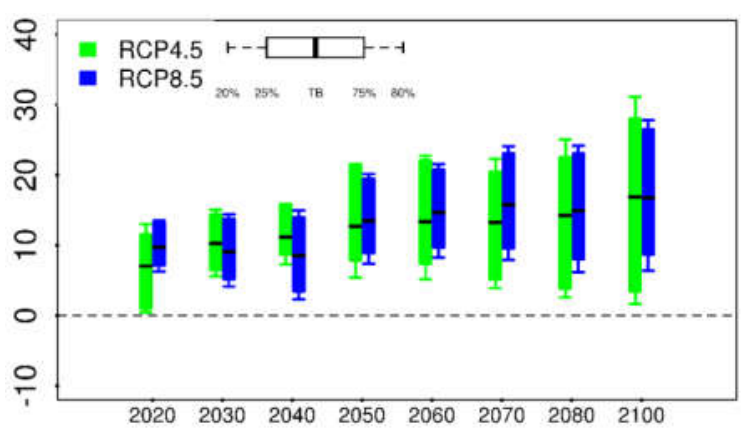

Hình 6. Mức độ chưa chắc chắn của các kịch bản về lượng mưa năm.

(vùng màu xanh dương, xanh lá cây là khoảng dao động của thay đổi lượng mưa năm từ phân vị 20 đến và phân vị 80 tương ứng với kịch bản RCP4.5 và RCP8.5).
Bảng 1. Biến đổi của nhiệt độ năm $\left({ }^{\circ} \mathrm{C}\right)$ và lượng mưa năm (\%) so với thời kỳ cơ sở.

(Giá trị trong ngoặc đơn là khoảng biến đổi quanh giá trị trung bình với cận dưới $10 \%$ và cận trên $90 \%$ với nhiệt độ; cận dưới $20 \%$ và cận trên $80 \%$ với lượng mưa).

\begin{tabular}{ccccc}
\hline \multirow{2}{*}{$\begin{array}{c}\text { Thời } \\
\text { kì }\end{array}$} & \multicolumn{2}{c}{ Nhiệt độ } & \multicolumn{2}{c}{ Lự̛ng mura } \\
\cline { 2 - 5 } & $\mathbf{R C P 4 . 5}$ & $\mathbf{R C P 8 . 5}$ & $\mathbf{R C P 4 . 5}$ & $\mathbf{R C P 8 . 5}$ \\
\hline $2016-$ & 0,7 & 0,9 & 16,7 & 14,7 \\
2035 & $(0,4 \div 1,2)$ & $(0,5 \div 1,3)$ & $(11,4 \div 21,3)$ & $(10,0 \div 19,3)$ \\
$2046-$ & 1,5 & 2,0 & 18,8 & 20,7 \\
2065 & $(1,0 \div 2,1)$ & $(1,4 \div 2,8)$ & $(10,5 \div 28,6)$ & $(14,6 \div 27,0)$ \\
$2080-$ & 1,9 & 3,5 & 22,7 & 23,4 \\
2099 & $(1,2 \div 2,7)$ & $(2,8 \div 4,7)$ & $(6,7 \div 37,5)$ & $(13,2 \div 33,9)$ \\
\hline & & & & \\
\hline
\end{tabular}

\section{Kết luận}

Kết quả nghiên cứu chi tiết hóa kịch bản BĐKH khu vực TPHCM cho thấy:

Nhiệt độ trung bình năm ở TPHCM trong tương lai đều có xu thế tăng lên so với thời kỳ cơ sở 1986 - 2005, mức tăng phụ thuộc vào các kịch bản RCP. Đến cuối thế kỷ, nhiệt độ trung bình năm ở TPHCM có mức tăng khoảng $1,7 \div 1,9^{\circ} \mathrm{C}$ theo kịch bản RCP4.5 và $3,2 \div 3,6^{\circ} \mathrm{C}$ theo kịch bản RCP8.5.

Lượng mưa năm ở TPHCM có xu thế tăng ở hầu hết các thời kỳ theo cả hai kịch bản RCP. Đến cuối thế kỷ, lượng mưa năm ở TPHCM tăng phổ biến từ 15 đến $25 \%$ theo kịch bản RCP4.5 và $20-25 \%$ theo kịch bản RCP8.5 . Lượng mưa năm ở khu vực ven biển tăng nhiều hơn so với khu vực sâu trong đất liền.

Qua phân tích về tính chưa chắc chắn của kịch bản $\mathrm{BĐKH}$, có thể thấy kết quả dự tính nhiệt độ và lượng mưa của TPHCM có dải biến đổi khá lớn, đặc biệt là đối với lượng mưa. Vì thế, khi sử dụng kịch bản $\mathrm{BĐKH} \mathrm{để} \mathrm{đánh} \mathrm{giá}$ tác động của $\mathrm{BĐKH}$, cần phân tích các khả năng có thể xảy ra trong tương lai của các biến khí hậu, tham vấn thêm ý kiến của chuyên gia để xác định các giá trị phù hợp. 


\section{Lời cảm ơn}

Nghiên cứu này được thực hiện và hoàn thành nhờ sự hỗ trợ của Đề tài "Nghiên cứu khả năng đáp ứng của hệ thống thoát nước trên địa bàn thành phố Hồ Chí Minh trong điều kiện biến đổi khí hậu". Tác giả xin chân thành cảm ơn.

\section{Tài liệu tham khảo}

[1] IPCC (1990), Contribution of Working Group 1 to the First Assessment Report of the Intergovernmental Panel on Climate Change, Cambridge University Press, Cambridge, United Kingdom; New York, NY, USA, p. 365.

[2] IPCC (1995), Contribution of Working Group I to the Second Assessment Report of the Intergovernmental Panel on Climate Change, Cambridge University Press, Cambridge, United Kingdom; New York, NY, USA, p. 588.

[3] IPCC (2001), Contribution of Working Group I to the Third Assessment Report of the Intergovernmental Panel on Climate Change, Cambridge University Press, Cambridge, United Kingdom; New York, NY, USA, p. 881.

[4] IPCC (2007), Contribution of Working Group I to the Fourth Assessment Report of the
Intergovernmental Panel on Climate Change, Cambridge University Press, Cambridge, United Kingdom; New York, NY, USA, p. 996.

[5] Bộ Tài nguyên Môi trường (2003), Thông báo lân thứ nhất của Việt Nam cho Công ước khung của Liên Hợp Quốc về Biến đổi khí hậu.

[6] Bộ Tài nguyên Môi trường (2009), Kịch bản Biến đổi khí hậu, nước biển dâng cho Việt Nam.

[7] Bộ Tài nguyên Môi trường (2012), Kịch bản Biến đổi khí hậu, nước biển dâng cho Việt Nam.

[8] Bộ Tài nguyên Môi trường (2016), Kịch bản Biến đổi khí hậu, nước biển dâng cho Việt Nam.

[9] IPCC (2013), Climate Change 2013: The Physical Science Basis. Contribution of Working Group I to the Fifth Assessment Report of the Intergovernmental Panel on Climate Change.

[10] Mishra, K., B. and Herath, S. (2014). Assessment of Future Floods in the Bagmati River Basin of Nepal Using Bias-Corrected Daily GCM Precipitation Data, J. Hydrol. Eng., 10.1061 /(ASCE) HE.1943-5584.0001090, 05014027.

[11] Amengual A, Homar V, Romero R, Alonso S, Ramis C (2012),A statistical adjustment of regional climate model outputs to local scales: application to Platja de Palma, Spain. J Clim 25:939-957.

\title{
Contructing Climate Change Scenarios for Ho Chi Minh City
}

\author{
Mai Van Khiem \\ Viet Nam Institute of Meteorology Hydrology and Climate Change, \\ 23/62 Nguyen Chi Thanh, Dong Da, Ha Noi
}

\begin{abstract}
This article presents the results of constructing climate change scenarios for Ho Chi Minh City (HCMC) based on the climate change scenarios of Vietnam published in 2016 by the Ministry of Natural Resources and Environment. Four high-resolution regional climate models including CCAM, clWRF, PRECIS, and RegCM were used to downscale the results of global climate models. The results show that the annual average temperature in HCMC tends to increase in the future compared to the baseline period 1986 - 2005, the increase depends on each RCP scenario. By the end of the century, the annual average temperature in $\mathrm{HCMC}$ has an increase of about $1.7 \div 1.9^{\circ} \mathrm{C}$ under the RCP4.5 scenario and $3.2 \div 3.6^{\circ} \mathrm{C}$ under RCP8.5. Meanwhile, annual rainfall in HCMC tends to increase in most periods under both of RCP scenarios. By the end of the century, annual rainfall in HCMC increases from $15 \%$ to $25 \%$ in the RCP4.5 and $20-25 \%$ in the RCP 8.5 scenarios, respectively. Annual rainfall in coastal areas increaseslarger than in inland areas.
\end{abstract}

Keywords: Climate change scenarios, Ho Chi Minh City. 